mit denen die oben angeführten zum Theil ziemlich nahe übereinstimmen, hat ibren Grund in der zu hohen Temperatur, bei welcher $R$ ichardson getrocknet hat. $P h$. hat dieses auch durch einen besondern Versuch bewiesen. Denn 70,25 Grm. $2 \dot{\mathrm{P}} \mathrm{b} \ddot{\mathrm{C}}+\dot{\mathrm{P}} \mathrm{b} \dot{\mathrm{H}}$, zehn Stunden lang bei $205^{\circ} \mathrm{C}$. $\left(400^{\circ} \mathrm{F}\right.$.) erhitzt, hatten 1,62 Grm. Wasser und 1,65 Grm. Kohlensăure verloren, also alles Wasser und $1 / 4$ der Kohlensäure, so dass das rückständige $S a l z$ aus $\dot{\mathrm{P}} b \ddot{\mathrm{C}}+\dot{\mathrm{P} b}$ bestand. Indessen muss hierbei bemerkt werden, dass in Bezug auf den Gehalt an Bleioxyd auch Richardson's Analysen zum Theil mit denen des Verf. übereinstimmen und es scheint nur die Abweichung darin $2 u$ liegen, dass sảmmtlicher Verlust als Kohlensäure angegeben ist.

\title{
XLI.
}

\section{Ueber eine Verbindung von Schwefel, Nickel und Wismuth.}

\author{
Von \\ ब. Werther.
}

Vor einiger Zeit erhielt ich von Herrn Prof. G. Ros e eine Druse durch einander gewachsener Krystalle, die sich zufälig beim Reinigen von käuflichem Wismuth gebildet hatten. Das Reinigen war vom Herrn Hofapotheker Wittstock nach Vorschrift der preussischen Pharmokopoe (VI. Ausg.) vorgenommen, indem $8 \mathrm{Th}$. Wismuth mit $1 \mathrm{Th}$. trocknem und gereinigten kohlensauren Natron und $1 / 8$ Th. Schwefel zusammengeschmolzen wurden. Als man dieses so gereinigte Wismuth auf die bekannte Weise zum Krystallisiren bringen wollte, fanden sich beim Ausgiessen des noch fiùssigen Metalls an den Wänden des Tiegels die oben erwăhnten Krystalle in grosser Menge vor. thre Form konnte Herr Prof. Ros e wegen der unvollkommenen Ausbildung nicht ermilteln. Sie hatten einen starken metallischen Glanz, dem des Wismuths ähnlich, aber weniger röthlich. Ihr spec. Gew. war $=9,15$ bei $+17,5^{\circ} \mathrm{C}$. in Pulverform bestimmt. Sie sind zerreiblich und sprőde, jedoch nicht in dem Grade wie Wismuth. Vor dem Löthrohr auf Kohle schmelzen sie in der 
228 Werther: Verbindung r. Schwefel, Nickel u. Wismuth.

reducirenden Flamme erst bei bedeutend höberer Temperatur als Wismuth zu einer weissen Kugel, aus welcher sich Wismuth vertlüchtigl; in der oxydirenden Flamme bildet sich der bekannte gelbe Beschlag um die Probe und wenn alles Wismuth verfuuchligt ist, bleibt eine unschmelzbare, schwärzlich-graue Masse übrig, die sich in Phosphorsalz mit der schmutzig grünen Farbe des Nickeloxyduls vollkommen löst. In ciner offenen Glasröbre erhitzt, entweicht schweflige Säure, aber erst bei der Temperatur, wo Glas weich wird und bierbei schmelzen sie noch nicht. In Salpetersāure lösen sie sich leicht auf unter Abscheidung von Schwefel.

Die quantitative Analvse auf nassem Wege ergab Wismuth, Nickel und Schwefel ohne Spuren von Kobait, Zinn, Antimon, Arsenik, Eisen oder Zink.

Die quantitative Analyse lieferte folgendes Resultat:

I. 1,215 Grm. gaben 1,186 Wismuthoxyd und 0,157 Grm. Nickeloxydul.

II. 2,06 Grm. gaben 0,05 Grm. Scliwefel, 0,338 Grm. schivefelsaure Baryterle, 0,268 Grm. Nickeloxydul und 1,99 Grm. Wismuthoxyd.

In 100 Theilen:

\begin{tabular}{lcccc} 
& & \multicolumn{3}{c}{ Nach dem } \\
Wismnth & $\mathbf{8 7 , 7 4}$ & 11. & \multicolumn{8}{c}{ Atomverhältniss berechnet } \\
Nickel & $\mathbf{1 0 , 1 2}$ & $\mathbf{1 0 , 2 3}$ & $\mathbf{1 2}$ & $\mathbf{8 7 , 6 7}$ \\
Schwefel & - & $\mathbf{2 , 2 8}$ & $\mathbf{5}$ & $\mathbf{1 0 , 1 3}$ \\
& & & 2,20
\end{tabular}

Die einfachste Formel würde demnach sein entweder: 2NiS $+3 \mathrm{NiBi}_{2}$, oder: $\mathrm{NiS}_{2}+4 \mathrm{NiBi}_{3}$. Weniger empfehlenswerth scheint $2 \mathrm{BiS}+5 \mathrm{NiBi}$, denn in Verbindung mit andern electropositiven Metallen ist Wismuth doch dem Arsenik und Antimon analog, und zufolge vieler Versuche, die ich früher mit der Verbindung BiS angestellt habe, ist letztere nicht geneigt, mit andern Schwefelverbindungen weder als Sulphobasis noch als Sulphosäure Verbindungen einzugehen; sie wird also auch wahrscheinlich nicht mit den, den Sulpbosäuren analogen Arsenik-, Antimon- oder Wismuth-Verbindungen Salze bilden. 